\title{
Trait Anxiety Modulates the Neural Efficiency of Inhibitory Control
}

\author{
Ulrike Basten $^{1,2}$, Christine Stelzel ${ }^{2,3}$, and Christian J. Fiebach ${ }^{1,2}$
}

\begin{abstract}
An impairment of attentional control in the face of threat-related distracters is well established for high-anxious individuals. Beyond that, it has been hypothesized that high trait anxiety more generally impairs the neural efficiency of cognitive processes requiring attentional control-even in the absence of threat-related stimuli. Here, we use fMRI to show that trait anxiety indeed modulates brain activation and functional connectivities between task-relevant brain regions in an affectively neutral Stroop task. In high-anxious individuals,
\end{abstract}

\section{INTRODUCTION}

Anxious people are easily distracted by threat-related information and are impaired in their ability to regulate attention to threatening stimuli. This attentional bias in favor of threat-related information is well established for both clinical anxiety and trait anxiety in the nonpathological range (Bar-Haim, Lamy, Pergamin, Bakermans-Kranenburg, \& van Ijzendoorn, 2007; Bishop, Duncan, Brett, \& Lawrence, 2004; Bishop, Duncan, \& Lawrence, 2004; Williams, Mathews, \& MacLeod, 1996; Fox, 1994). It is attributed to an imbalance in the interplay between two attentional systems, that is, an amygdala-centered threat detection system that is hyperresponsive in anxious individuals and a prefrontal attentional control system that is critical for the inhibition of irrelevant and distracting information and that is assumed to be weakened in anxious individuals (Bishop, 2007; Eysenck, Derakshan, Santos, \& Calvo, 2007; Öhman, 2005; Mathews \& Mackintosh, 1998). Currently, however, it is still an open question if the impairment of attention control is specific to threat-related information or if it applies more generally to all kinds of situations requiring the topdown control of attention.

It has been hypothesized that trait anxiety generally impairs attentional control in cognitively challenging situations, requiring the inhibition of distracting or irrelevant information-no matter what kind of information has to be ignored (Bishop, 2009; Eysenck et al., 2007; Derryberry \& Reed, 2002; Fox, 1993, 1994). At the level of overt performance, however, the empirical evidence for the proposed general impairment of attentional control in

${ }^{1}$ Goethe University Frankfurt, ${ }^{2}$ University of Heidelberg, ${ }^{3}$ Charité Universitätsmedizin, Berlin, Germany dorsolateral $\mathrm{pFC}$ showed stronger task-related activation and reduced coupling with posterior lateral frontal regions, dorsal ACC, and a word-sensitive area in the left fusiform gyrus. These results support the assumption that a general (i.e., not threat-specific) impairment of attentional control leads to reduced neural processing efficiency in anxious individuals. The increased dorsolateral pFC activation is interpreted as an attempt to compensate for suboptimal connectivity within the cortical network subserving task performance. anxious people is inconsistent. In cognitive tasks placing demands on attentional control, anxious subjects sometimes did (e.g., Eysenck, Payne, \& Derakshan, 2005; MacLeod \& Donnellan, 1993), but sometimes did not (e.g., Blankstein, Toner, \& Flett, 1989; Calvo, 1985; Eysenck, 1985), show impairments in behavioral performance. This led to the influential hypothesis that, in tasks requiring attentional control, anxiety impairs processing efficiency more than performance effectiveness (in the following we will refer to this idea as the processing efficiency account of anxiety and cognition; for the basic idea, see "processing efficiency theory," Eysenck \& Calvo, 1992; for a recent reformulation and extension, see "attentional control theory," Eysenck et al., 2007). Eysenck et al. (2007) assume that although performance effectiveness, that is, the quality of overt performance, often is preserved, anxious people have to invest compensatory effort to reach a standard level of performance. Cognitive processing that requires attentional control, therefore, is assumed to be less efficient in anxious individuals.

Given that the processing efficiency account does not make clear predictions with respect to the effects of anxiety on overt performance, measures like accuracy and response times are inadequate to test the theory. Anxious subjects may or may not be able to avoid detriments of overt performance by the investment of additional effort. The effects depend on task difficulty and anxiety level (for theoretical claim, see Eysenck et al., 2007; Eysenck \& Calvo, 1992; for empirical evidence, see Eysenck et al., 2005; Ashcraft \& Kirk, 2001; Calvo, Ramos, \& Estevez, 1992). Consequently, to test the theory, we need to test the predictions concerning processing efficiency. For that purpose, a measure of the effort associated with task 
performance is required. fMRI of the brain provides one such measure that quantifies task-related effort in the form of neural activity elicited during cognitive processing. The BOLD signal provides an index of neural effort that can be related to behavioral performance to derive an estimate of the efficiency of cognitive processing.

Up to now, only very few studies have applied fMRI to investigate the association of task-related neural effort with anxiety. These studies, however, have lead to contradictory results. Fales et al. (2008), in accordance with the processing efficiency account, report stronger activation of a cognitive control network (including the dorsolateral pFC [DLPFC]) in anxious subjects for trial to trial adjustments of cognitive control in a verbal 3-back task. Bishop (2009), on the contrary, reports weaker activation of the left DLPFC for anxious subjects in a distracter inhibition paradigm. The two studies differ in various aspects - ranging from the behavioral paradigms employed to the statistical comparisons conducted-that may account for the inconsistent findings. Specifically, the unexpected weaker activation in anxious subjects (Bishop, 2009) is specific to high cognitive conflict under low perceptual load but not observed under increased perceptual load. The $n$-back task used by Fales et al. (2008), on the other hand, is a demanding working memory task that engages multiple executive functions (e.g., updating and maintenance), rendering it impossible to specify which component function is impaired in anxious subjects.

In view of these inconsistent findings from initial studies employing rather complex paradigms, we focused on a single executive function, that is, inhibition, and directly tested the predictions of the processing efficiency account. According to Eysenck et al. (2007), inhibition is one of two critical functions of the executive attention system impaired by anxiety. To experimentally assess inhibition, we used the color word Stroop task (Stroop, 1935), an established paradigm that poses high demands on inhibitory control. Participants must ignore irrelevant stimulus information and overcome a prepotent yet unwanted response (i.e., to read a color word on the screen while naming the color in which it is presented; cf. Miyake et al., 2000, for an empirical motivation of this task choice). Demands on other executive functions, such as updating, maintenance, or monitoring, can be precluded in this task.

The core regions implicated in the Stroop incongruency effect are the ACC, which supposedly monitors for conflicts in cognitive processing, the DLPFC, assumed to exert executive control to inhibit irrelevant representations (Botvinick, Cohen, \& Carter, 2004; MacDonald, Cohen, Stenger, \& Carter, 2000) and the posterior pFC at the junction of the inferior frontal and precentral sulci (inferior frontal junction area [IFJ]; Derrfuss, Brass, Neumann, \& von Cramon, 2005), supposedly subserving the updating of relevant representations. As effects of anxiety are specifically expected for the exertion of inhibitory control, we predicted a positive correlation between trait anxiety (as measured using the State Trait Anxiety Inventory; Spielberger,
Gorsuch, Lushene, Vagg, \& Jacobs, 1983) and the strength of incongruency-related neural activation in DLPFC.

In addition, we reasoned that the influence of anxiety on cognitive processing is not mediated by regional activation differences alone but also by the quality of functional interactions between brain regions involved in task processing. This assumption is motivated by recent studies that demonstrated an important role of differences in interregional coupling for optimal versus suboptimal or even pathological cognitive processing, for example, for high as compared with low intelligence (Neubauer \& Fink, 2009b) and for psychiatric disorders such as schizophrenia (Meda, Stevens, Folley, Calhoun, \& Pearlson, 2009; Spoletini et al., 2009; Stephan, Baldeweg, \& Friston, 2006; Meyer-Lindenberg et al., 2005; Schlösser et al., 2003; Friston, 1998), depression (Vasic, Walter, Sambataro, \& Wolf, 2009; Schlösser, Wagner, et al., 2008), and anxiety disorders (Etkin, Prater, Schatzberg, Menon, \& Greicius, 2009; Shaw et al., 2009). Of greatest relevance to the present study is the finding that anxiety-related personality traits are accompanied by reduced amygdalaprefrontal connectivity in emotion regulation tasks requiring cognitive control for the modulation of an affective response (Cremers et al., 2010; Kienast et al., 2008; Passamonti et al., 2008). Analogous to these results, we predicted that, during performance of the affectively neutral Stroop task, anxious subjects should show a reduction of functional connectivity in the task-relevant network - which might be the cause of compensatory increases in regional neural activity of prefrontal control regions.

\section{METHODS \\ Participants}

Forty-eight paid healthy volunteers participated in a training session and the following fMRI experiment. All were students of University of Heidelberg, right-handed, had normal or corrected-to-normal vision, no structural brain abnormalities, and no history of psychiatric or neurological diseases according to self-report in a telephone interview. Informed consent was obtained in conformity with a protocol approved by the local ethics committee. Data of two subjects were excluded. In one case, imaging data were incomplete. The other case was identified as an extreme outlier regarding the main individual differences variable, trait anxiety. The State Trait Anxiety Inventory trait score (raw score $=60$ ) was 3.8 SD above the current sample's mean (all other subjects were within $\pm 2 S D$ ). With respect to the German normative sample that was above the 99th percentile (standard score $T=75$; Laux, Glanzmann, Schaffner, \& Spielberger, 1981). We reasoned that in this case we could not exclude a pathological form of anxiety, incompatible with our aim to investigate mechanisms of anxiety in the normal, nonpathological range. Of the remaining 46 participants (19-27 years; $M=22.3, S D=$ 2.0), 22 were women. Trait anxiety raw scores ranged from 24 to $46(M=33.3, S D=5.7)$, which is comparable to the 
values of the German normative sample of similar age and education $(M=34.7, S D=8.4$; Laux et al., 1981). For some of the reported analyses, the sample was median-split into a low-anxious and a high-anxious group, differing significantly in trait anxiety scores (low-anxious group: $M=$ 28.6; high-anxious group: $M=38.1 ; t(44)=10.3, p<$ $.001)$, but not differing with respect to intelligence as assessed using the advanced progressive matrices (APM; Raven, Raven, \& Court, 1998; $t(44)=0.70, p=.50)$.

\section{Behavioral Procedure}

Participants performed a manual version of the color word Stroop task adapted for application in an MRI scanner (Van Veen \& Carter, 2005; De Houwer, 2003). Subjects responded with their left index finger when a color word was presented in red or yellow and with their right index finger when it was in blue or green. The task included congruent trials where font color and meaning of the word matched and incongruent trials where color and meaning did not match. For the present study, no further distinction was made between semantically and response-incongruent stimuli (cf. De Houwer, 2003). The Stroop task was combined with a stop-signal paradigm. Stop-signal trials are not considered here, and data will be reported elsewhere. Participants were trained on the task before the fMRI session for about $15 \mathrm{~min}$. The fMRI experiment took $20 \mathrm{~min}$, comprising two blocks of 128 trials each. Visual stimuli were presented on a dark background in the center of the screen, using Presentation (Neurobehavioral Systems, nbs.neuro-bs.com/). Stimuli were presented in pseudorandom order with $50 \%$ congruent and 50\% incongruent trials and no more than three trials of the same type presented in a sequence. Twenty-five percent of all trials were stop trials, so that the results reported are on the basis of 96 nonstop Stroop trials per block. Subjects were instructed to respond fast and accurately. Presentation times for the stimuli were $300 \mathrm{msec}$ for word stimuli and 1700, 3700, or $5700 \mathrm{msec}$ for a fixation cross presented between words, which led to a jitter of intertrial intervals (Dale, 1999). Responses were registered from the onset of the stimulus until $800 \mathrm{msec}$ after stimulus offset.

\section{fMRI Procedures}

MRI data were acquired on a Siemens Trio 3 T MRI scanner equipped with a fast gradient system for EPI and a birdcage head coil. Participants were stabilized with cushions to restrict head motion comfortably. Functional data were acquired using a T2*-weighted BOLD-sensitive gradient-echo, EPI sequence with 32 oblique axial slices (thickness $=3 \mathrm{~mm}$, interslice gap $=1 \mathrm{~mm}$, field of view $=192 \mathrm{~mm}$, matrix size $=$ $64 \times 64$, in-plane resolution $=3 \times 3 \mathrm{~mm}$, repetition time $=$ $2500 \mathrm{msec}$, echo time $=30 \mathrm{msec}$, flip angle $=80^{\circ}$ ). Two runs of 240 volumes each were acquired. The first six volumes of both runs were discarded to allow for stable magnetization. For coregistration, a T1-weighed anatomical scan with identical slice prescription as the functional scans was acquired. Three-dimensional high-resolution anatomical data were obtained via a sagittal T1-weighted, Magnetization Prepared-Rapid Gradient Echo scan with 192 slices (thickness $=1 \mathrm{~mm}$, field of view $=256 \mathrm{~mm}$, matrix size $=256 \times 256$, in-plane resolution $=1 \times 1 \mathrm{~mm}$, repetition time $=1570 \mathrm{msec}$, echo time $=2.63 \mathrm{msec}$, flip angle $=30^{\circ}$ )

\section{fMRI Data Analyses}

All fMRI analyses were carried out using the Statistical Parametric Mapping software package (SPM5, Wellcome Department of Cognitive Neurology, London, UK, www.fil. ion.ucl.ac.uk/spm/spm5.html). The acquired EPI time series were first slice-time and then motion corrected. All functional volumes were spatially normalized (MNI 152) according to parameters resulting from the segmentation of the high-resolution anatomies (voxels resampled to $2 \times$ $2 \times 2 \mathrm{~mm}$ ). Finally, spatial smoothing was applied (8 mm FWHM Gaussian kernel). Statistical modeling consisted of an individual model for each participant, followed by group-level analyses treating participants as random effects. Analyses were performed using general linear models (GLMs) applying a canonical hemodynamic response function and its temporal derivative (Friston et al., 1998) and a temporal high-pass filter (cutoff at $128 \mathrm{sec}$ ). Functional runs were modeled as separate sessions. The GLM included regressors for congruent, incongruent (response incongruent and semantically incongruent), and stop trials as well as covariates of no interest for incorrectly answered trials and realignment parameters. Only the Stroop taskrelated regressors for congruent and incongruent trials are considered for the present report.

Throughout the study, we applied a significance level of $5 \%$, corrected. Protection against false positives was achieved by combining a voxel probability threshold with a nonarbitrary minimum cluster size threshold. This approach is based on the assumption that meaningful activation in fMRI is spatially clustered and that this clustering provides protection against Type 1 error (Forman et al., 1995). For a given voxel-level threshold, the required minimum cluster size was determined for every single analysis via Monte Carlo simulation using the AFNI routine AlphaSim (Ward, 2000). Taking into consideration, the fact that the power to detect between-subject effects is typically much lower than the power to detect within-subject effects (cf. Yarkoni \& Braver, 2010; Yarkoni, 2009), we applied distinct voxel thresholds when testing for task effects in the withinsubject analyses ( $p<.001$, uncorrected) and when testing for anxiety effects in the between-subject analyses $(p<$ .005 , uncorrected). By combining the voxel thresholds with cluster size thresholds (see above), we maintained consistent protection against false positives for all analyses reported ( $p<.05$, corrected). The cluster size thresholdsspecific to the respective analyses — are reported in the following sections. 


\section{Task-related Activation}

Task-related activation was identified by contrasting incongruent and congruent Stroop trials. This contrast most specifically reflects the neural effort invested for the control of attention to inhibit irrelevant stimulus information and the respective response (cf. Derrfuss, 2005; Kerns et al., 2004; Pardo, Pardo, Janer, \& Raichle, 1990). We applied an overall threshold of $p<.05$ (corrected for multiple comparisons), constituted by an individual voxel probability threshold of $p<.001$ (uncorrected, $t(45)>$ $3.3)$, in combination with a minimum cluster size threshold of $k>71$ voxels. The threshold was determined using AlphaSim (Ward, 2000) to model the entire functional image matrix.

\section{Effects of Anxiety on Task-related Activation}

A multiple regression model was set up at the group level to test whether the strength of task-related activity could be predicted by trait anxiety. Performance accuracy was included as a covariate of no interest. When testing for the effects of anxiety in this model, we only see where performance-independent variance components of anxiety explain brain activation. In a second model, we additionally included intelligence (APM) as a second covariate of no interest to account for potential effects of intellectual ability on neural effort, as general cognitive ability has been linked to processing efficiency as well (Neubauer \& Fink, 2009a). As we specifically predicted effects of anxiety on brain activation for the bilateral DLPFC (see Introduction), we restricted the regression analyses to this region by applying an anatomical mask. The DLPFC mask was generated based on the Talairach Daemon database (Lancaster et al., 2000; Lancaster, Summerlin, Rainey, Freitas, \& Fox, 1997) using the WFU PickAtlas in SPM (Maldjian, Laurienti, Kraft, \& Burdette, 2003). To cover DLPFC bilaterally, the mask comprised Brodmann's areas 46 and 9 (cf. Nee, Wager, \& Jonides, 2007; Banich et al., 2000a, 2000b; MacDonald et al., 2000), with a dilation factor of 2 to assure that all cortical surface within the relevant Brodmann's areas was covered and to account for individual variability in prefrontal anatomy. Medial frontal portions of the WFU template for BA 46/BA 9 were excluded by intersecting the mask with the Talairach Daemon template for the middle frontal gyrus, and nonbrain voxels included after dilation were excluded by intersection with the wholebrain mask generated during group analysis. Group statistical parametric maps for the modulation of taskrelated activation by trait anxiety are reported applying an overall threshold of $p<.05$ (corrected for multiple comparisons), constituted by an individual voxel probability threshold of $p<.005$ (uncorrected, $t(45)>2.69$ ) in combination with a minimum cluster size threshold of $k>32$ voxels. The threshold was determined using AlphaSim (Ward, 2000) to model the anatomical ROI, that is, all voxels included in the bilateral DLPFC mask.

\section{Psychophysiological Interaction Analyses}

To investigate whether trait anxiety modulates the taskspecific functional coupling of the DLPFC with distal brain regions, we conducted a psychophysiological interaction (PPI) analysis (Friston et al., 1997). In the single-subject PPI analyses, GLMs contained three regressors: a P regressor, representing the psychological variable (i.e., the task contrast "incongruent vs. congruent"), a Y regressor, representing the physiological variable (i.e., the mean time course from the prefrontal cluster showing significant modulation of regional task activation by anxiety in the preceding analysis), and a PPI regressor, representing the interaction of the psychological and the physiological regressor. In the group-level analyses, regression models were set up to test whether the parameter estimates of the interaction terms could be predicted by trait anxiety. Again, our main regression model included behavioral accuracy as a covariate of no interest, whereas a second regression model additionally considered differences in intelligence (APM). PPI analyses were restricted to regions showing Stroop incongruency effects, as our focus was on the functional coupling of task-relevant regions. Statistical maps testing for the modulation of DLPFC functional connectivity by trait anxiety are reported applying an overall threshold of $p<.05$ (corrected for multiple comparisons), constituted by an individual voxel probability threshold of $p<.005$ (uncorrected, $t(45)>2.69$ ) in combination with a minimum cluster size threshold of $k>67$ voxels. The threshold was determined using AlphaSim (Ward, 2000) to model the functionally defined VOI, that is, all regions showing a Stroop incongurency effect.

\section{Off-line Illustration of Activation Patterns}

From the regions showing a significant effect of trait anxiety (on regional activation or functional connectivity), we extracted estimates of activation strength, namely individual contrast values, to illustrate the pattern of activation and connectivity as depending on anxiety and experimental condition. We refrained from secondary statistical analyses on the data plotted (we did not calculate correlations or test for significance) to avoid problems of nonindependent testing (Poldrack \& Mumford, 2009; Vul, Harris, Winkielman, \& Pashler, 2009). Scatterplots serve to demonstrate that correlations are not driven by outliers. Barplots disentangle effects of task condition (incongruent vs. congruent) and anxiety (high vs. low) on regional task activation.

\section{RESULTS}

\section{Behavioral Results}

For incongruent as compared with congruent trials, increases were observed in error rates $(F(1,44)=45.10$, $p<.001)$ as well as response times $(F(1,44)=85.39$, $p<.001$; cf. Table 1$)$. The effect of trait anxiety (high vs. low) on errors did not reach significance $(F(1,44)=1.76$, 
Table 1. Mean Error Rates and Response Times in the Stroop Task

\begin{tabular}{llcc}
\hline Condition & Sample & Errors (\%) & $\begin{array}{c}\text { Response Times } \\
(\mathrm{msec})\end{array}$ \\
\hline Overall & Whole sample & $8.07(0.94)$ & $624.55(8.71)$ \\
& Low anxious & $6.84(1.06)$ & $640.00(11.45)$ \\
& High anxious & $9.31(1.53)$ & $609.09(12.56)$ \\
Congruent & Whole sample & $4.85(0.81)$ & $592.10(9.73)$ \\
& Low anxious & $4.71(1.04)$ & $609.75(12.13)$ \\
& High anxious & $4.98(1.27)$ & $574.45(14.56)$ \\
Incongruent & Whole sample & $11.30(1.27)$ & $640.77(8.70)$ \\
& Low anxious & $8.97(1.23)$ & $655.12(11.94)$ \\
& High anxious & $13.63(2.14)$ & $626.41(12.18)$ \\
Stroop Effect & Whole sample & $6.45(1.01)$ & $48.67(5.23)$ \\
& Low anxious & $4.26(0.87)$ & $45.37(7.63)$ \\
& High anxious & $8.65(1.72)$ & $51.97(7.26)$ \\
\hline
\end{tabular}

Performance measures are reported for the whole sample (overall $N=46$ ) as well as for the median-split derived subgroups of low-anxious $(n=23)$ and high-anxious $(n=23)$ participants. Standard errors are given in brackets.

$p=.19)$, but there was a trend toward faster responses for high-anxious subjects $(F(1,44)=3.45, p=.07)$. The interaction of task condition and trait anxiety was significant for error rates $(F(1,44)=5.22, p=.03)$ but not for response times $(F(1,44)=0.39, p=.54)$. Compared with the lowanxious group, the high-anxious group showed a significantly stronger Stroop incongruency effect in error rates, that is, a greater impairment of accuracy for incongruent as compared with congruent trials (see Figure 1). Correlational

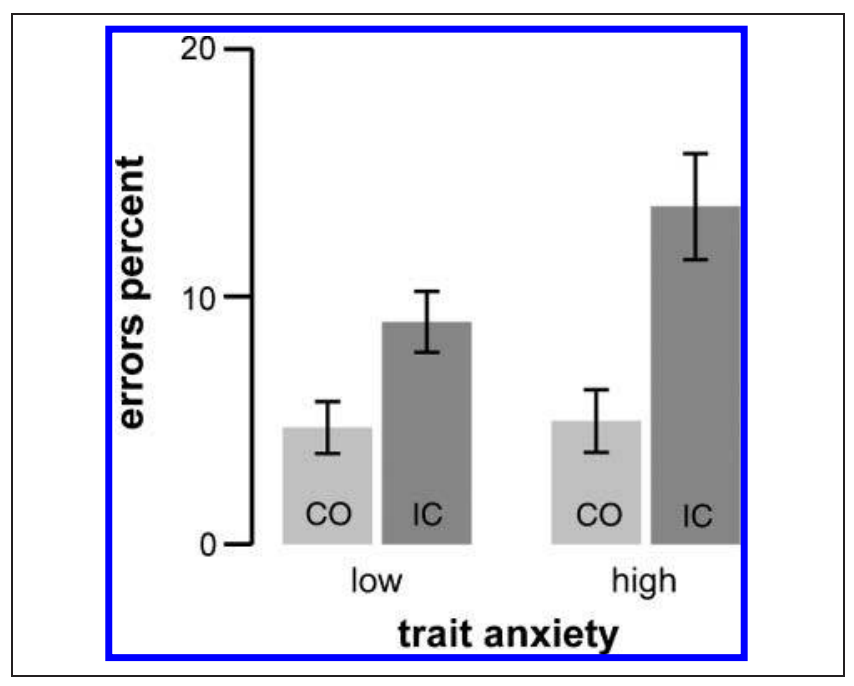

Figure 1. Interaction of trait anxiety and task condition on accuracy in the Stroop task. Mean error rate by trait anxiety group (high vs. low) and task condition (incongruent vs. congruent). Light gray (CO): congruent; dark gray (IC): incongruent. Error bars show the SEM.
Table 2. Correlations with Trait Anxiety for Performance Measures from the Stroop Task by Condition

\begin{tabular}{lcc}
\hline Condition & Errors & Response Times \\
\hline Overall & $.15(.320)$ & $-.25(.096)$ \\
Congruent & $-.02(.874)$ & $-.23(.125)$ \\
Incongruent & $.24(.112)$ & $-.24(.102)$ \\
Stroop Effect & $\mathbf{. 3 2}(.031)$ & $.02(.891)$ \\
\hline
\end{tabular}

$p$ Values are given in brackets. Significant correlations $(p<.05)$ are set in bold type.

analyses (Table 2) confirmed the results of the ANOVA. There was a significant association between trait anxiety scores and the Stroop incongruency effect in error rates $(r=.32, p<.05)$. For response times (across conditions), a trend toward a negative association with trait anxiety was observed that-like in the group comparison-failed to reach statistical significance $(r=-.25, p=.096)$.

\section{fMRI Results}

\section{Incongruency Effects in the Stroop Task}

As expected on the basis of previous studies, brain activity was increased for incongruent as compared with congruent trials in a set of regions including the lateral prefrontal, medial frontal, parietal, and occipito-temporal cortex (Figure 2 and Table 3). Clusters of activation were located medially in the dorsal ACC (dACC), bilaterally in the lateral $\mathrm{pFC}$, with distinct peaks in DLPFC and IFJ, and in the intraparietal sulcus (extending into the precuneus). Incongruency furthermore modulated activation bilaterally in the temporal lobe, the BG (peak in the globus pallidus, activation extending into the striatum, that is, caudate head and putamen), and in the cerebellum. In the left hemisphere, the temporal activations comprised parts of the inferior temporal gyrus and the fusiform gyrus, whereas it was restricted to middle temporal gyrus in the right hemisphere.

\section{Effects of Trait Anxiety on Task-related Activation}

Within the ROI, that is, the bilateral DLPFC (cf. Experimental Methods), an area in the right DLPFC was identified where trait anxiety predicted the strength of task-related activation (MNI peak coordinates: $523626, k=42$ ). In this part of the DLPFC, high-anxious subjects showed a stronger increase in brain activation for incongruent as compared with congruent trials than low-anxious individuals (Figure 3A). Most importantly, trait anxiety explained variations in activation strength that could not be accounted for by behavioral performance differences (as performance accuracy was included as a covariate of no interest in the regression model predicting task activation by anxiety; cf. 


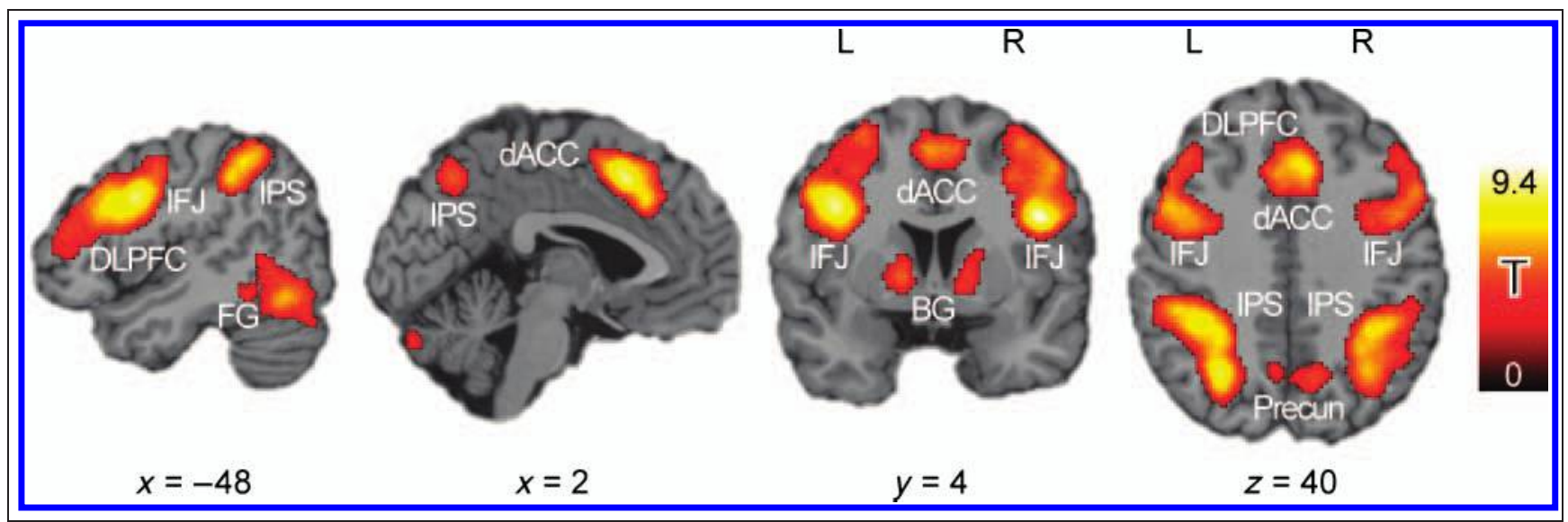

Figure 2. Brain activation for the Stroop task (incongruent $>$ congruent). Results displayed at $p<.001, k>71$. FG $=$ fusiform gyrus; IPS = intraparietal sulcus; Precun = precuneus.

Methods). The results indicate that trait anxiety modulates the neural effort exhibited for processing incongruency in the right DLPFC, such that higher trait anxiety goes along with greater neural effort. None of the regions included in the analysis showed the opposite pattern, that is, a significant negative correlation between anxiety and neural activation. Figure 3B illustrates the positive association between anxiety and brain activation. Finally, it is important to note that the anxiety effects were specific to the task condition of interest (i.e., incongruent trials) and were not attributable to a reverse effect in the reference condition (i.e., congruent trials). Figure 3C illustrates that for the reference condition (congruent $>$ baseline) the high-anxious and the low-anxious group did not differ in their level of activation $(t(44)=0.91, p=.37)$. Yet the high-anxious group showed a significantly greater increase in activation for the task comparison of interest (incongruent $>$ congruent). Considering individual differences in intelligence-in addition to effects of task performancechanged the results only marginally. The peak coordinates of the cluster where anxiety explained task-related activation remained unchanged. Although the cluster shrunk to a size of $k=35$ voxels, the incremental contribution of anxiety in explaining activation strength - beyond what could already be explained by performance and intelligence-was still significant. When extending the analysis to include not only the DLPFC but the whole brain, no further region showed significant modulation of brain activation by trait anxiety.

Table 3. Clusters of Brain Activation for the Stroop Task (Incongruent $>$ Congruent)

\begin{tabular}{|c|c|c|c|c|c|c|c|}
\hline \multirow[b]{2}{*}{ Brain Region } & \multirow[b]{2}{*}{$B A$} & \multirow[b]{2}{*}{$\mathrm{Hem}$} & \multicolumn{3}{|c|}{ MNI Coordinates } & \multirow[b]{2}{*}{ Voxel $t$} & \multirow[b]{2}{*}{ Cluster Size } \\
\hline & & & $x$ & $y$ & $z$ & & \\
\hline \multirow[t]{2}{*}{ DLPFC } & $46 / 9 / 44 / 8 / 6$ & $\mathrm{~L}$ & -42 & 6 & 30 & 8.61 & 3767 \\
\hline & $46 / 9 / 44 / 8 / 6$ & $\mathrm{R}$ & 42 & 6 & 26 & 9.35 & 3800 \\
\hline Ventrolateral pFC & 45 & $\mathrm{R}$ & 52 & 18 & 4 & 4.03 & 74 \\
\hline dACC & $24 / 32 / 6$ & $\mathrm{~L} / \mathrm{R}$ & 2 & 16 & 48 & 8.53 & 1575 \\
\hline \multirow[t]{2}{*}{ Intraparietal sulcus, precuneus } & $40 / 39 / 7$ & $\mathrm{~L}$ & -30 & -62 & 42 & 8.62 & 3372 \\
\hline & $40 / 39 / 7$ & $\mathrm{R}$ & 36 & -46 & 42 & 7.02 & 2109 \\
\hline Middle temporal gyrus & 37 & $\mathrm{R}$ & 56 & -48 & -14 & 5.01 & 198 \\
\hline $\begin{array}{l}\text { Middle temporal gyrus, inferior temporal } \\
\text { gyrus, fusiform gyrus, cerebellum }\end{array}$ & $37 / 19$ & $\mathrm{~L}$ & -48 & -62 & -16 & 6.17 & 1976 \\
\hline \multirow{2}{*}{$\begin{array}{l}\text { BG (globus pallidus, putamen, } \\
\text { caudate nucleus) }\end{array}$} & & $\mathrm{L}$ & -16 & 2 & 2 & 5.24 & 186 \\
\hline & & $\mathrm{R}$ & 12 & 6 & 0 & 4.59 & 187 \\
\hline Cerebellum & & $\mathrm{L} / \mathrm{R}$ & 12 & -76 & -28 & 6.80 & 1576 \\
\hline
\end{tabular}

$\mathrm{BA}=$ approximate Brodmann's area; Hem = hemisphere; $\mathrm{L}=$ left; $\mathrm{R}=$ right. MNI coordinates refer to the Montreal Neurological Institute template brain included into the SPM5 software package. 
Figure 3. Effects of trait anxiety on regional activation in the Stroop task. (A) Trait anxiety predicts BOLD signal strength in the Stroop task for an area in the right DLPFC. Results displayed at $p<.01$ for illustration purposes. (B, C) Plots display contrast values extracted from the right DLPFC region where anxiety significantly predicted task activation. (B) Individual contrast values for the task (incongruent $>$ congruent) by residual of trait anxiety. The residual results from the regression of anxiety on accuracy. (C) Comparison of mean contrast values for task (incongruent $>$ baseline, dark gray) and reference condition (congruent $>$ baseline, light gray) by trait anxiety group. Error bars show the SEM.

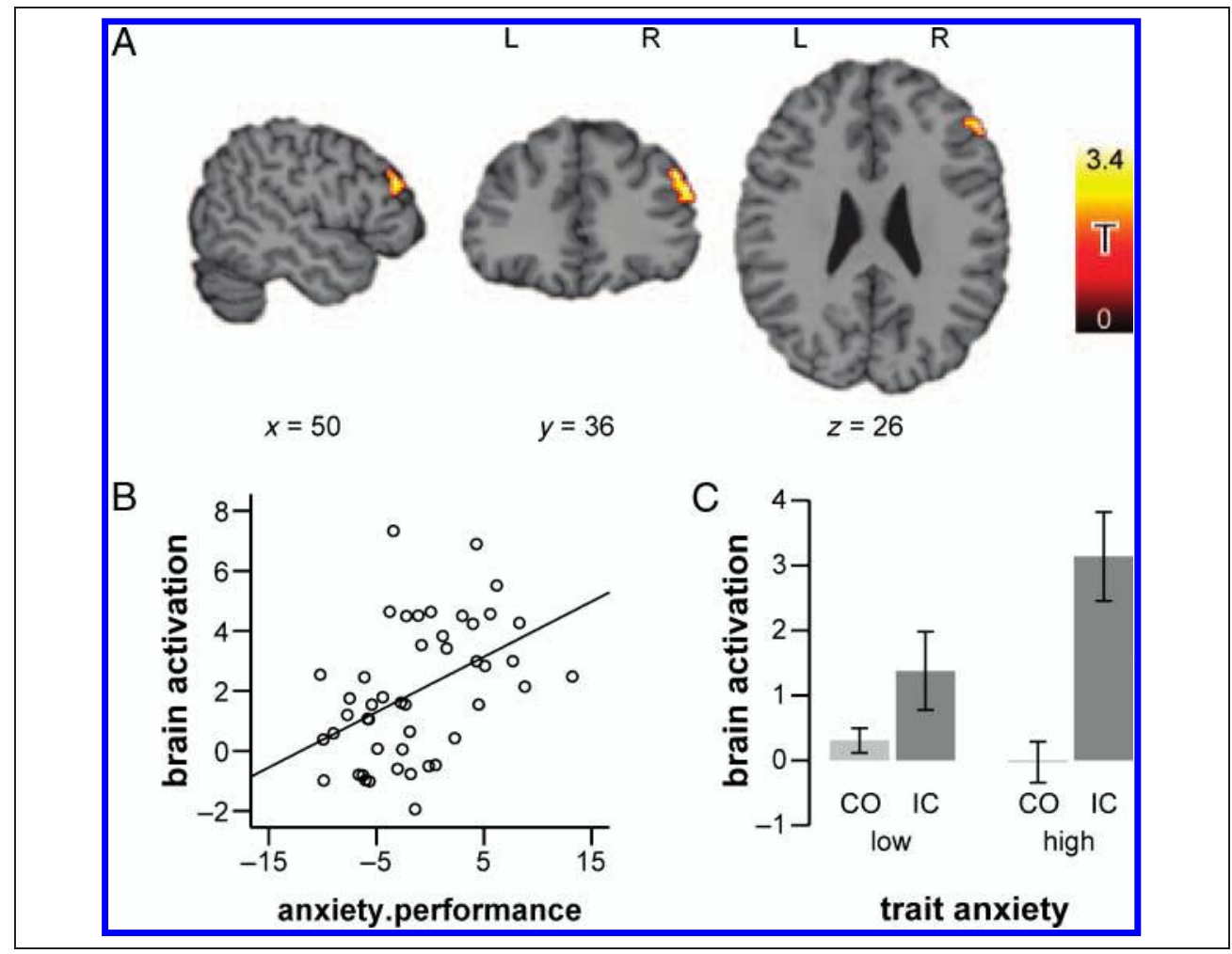

\section{Effects of Trait Anxiety on Cortico-cortical Functional Connectivity}

Trait anxiety predicted the task-specific coupling of the DLPFC seed region with the IFJ bilaterally, the dACC, and the left fusiform gyrus (Figure 4A and Table 4). Specifically, these regions showed significantly weaker task-specific coupling for high-anxious subjects than for low-anxious subjects (Figure $4 \mathrm{~B}$ ). No region showed the opposite pattern. Including intelligence in the prediction of connectivity strength changed the results only marginally. Although the clusters showing a significant modulation of connectivity by trait anxiety had the same MNI peak coordinates in the two analyses, cluster sizes varied slightly. Table 4 reports cluster sizes for the regression model with and without IQ.

\section{DISCUSSION}

In the current study, we investigated whether trait anxiety impairs the neural efficiency of attentional control processes in affectively neutral settings that require to suppress the processing of an irrelevant stimulus dimension and to inhibit the associated response. Comparing incongruent with congruent trials of a color word Stroop task, in trait anxious individuals we observed (a) stronger neural activation of a discrete task-relevant region implicated in inhibitory control (DLPFC) and (b) reduced functional connectivity between this control region and other regions of a taskrelevant cerebral network (IFJ, dACC, and left fusiform gyrus). Taken together, increased regional activation and decreased functional connectivity both support the assumption that neural processing efficiency is impaired in highanxious individuals for affectively neutral tasks requiring attentional control.

\section{Stroop Incongruency Effect}

The activation associated with the Stroop task, across all participants, is consistent with the results of previous studies that found activation in medial frontal cortex (ACC and pre-SMA), lateral frontal cortex (DLPFC and IFJ), and parietal cortex (Derrfuss et al., 2005; Van Veen \& Carter, 2005; Kerns et al., 2004; Banich et al., 2000a, 2000b; MacDonald et al., 2000; Pardo et al., 1990). Whereas ACC supposedly monitors for conflicts in cognitive processing, the DLPFC is assumed to be responsible for the adaptive implementation of control (Botvinick et al., 2004; MacDonald et al., 2000) and the IFJ supposedly subserves the updating of relevant representations (Derrfuss et al., 2005). The left temporal activation cluster comprises a region in the fusiform gyrus that is typically activated for word reading (McCandliss, Cohen, \& Dehaene, 2003) but is also subject to prefrontal top-down recruitment during word-related tasks, for instance, during verbal working memory maintenance (Fiebach, Rissman, \& D'Esposito, 2006). This inferotemporal region has been implicated in visual word recognition within the visual ventral stream and was labeled the visual word form area (Cohen et al., 2000). Prior studies investigating the neural correlates of the Stroop task have associated this region with the processing of the-not 
Figure 4. Effects of trait anxiety on functional coupling in the Stroop task. (A) Brain regions (middle row; bluegreen) showing anxietymodulated functional connectivity with right DLPFC seed (top row; red). Results displayed at $p<.01$ for illustration purposes. $\mathrm{FG}=$ fusiform gyrus. (B) Individual strength of PPI with the DLPFC seed region by trait anxiety score. Plots directly correspond to the regions named above, in the respective column of (A). PPI estimate $=$ contrast value of the interaction regressor in the PPI model, anxiety.performance = residuum of trait anxiety from regression on behavioral performance. The scale of the ordinate given in the plot to the left is valid for all four plots.

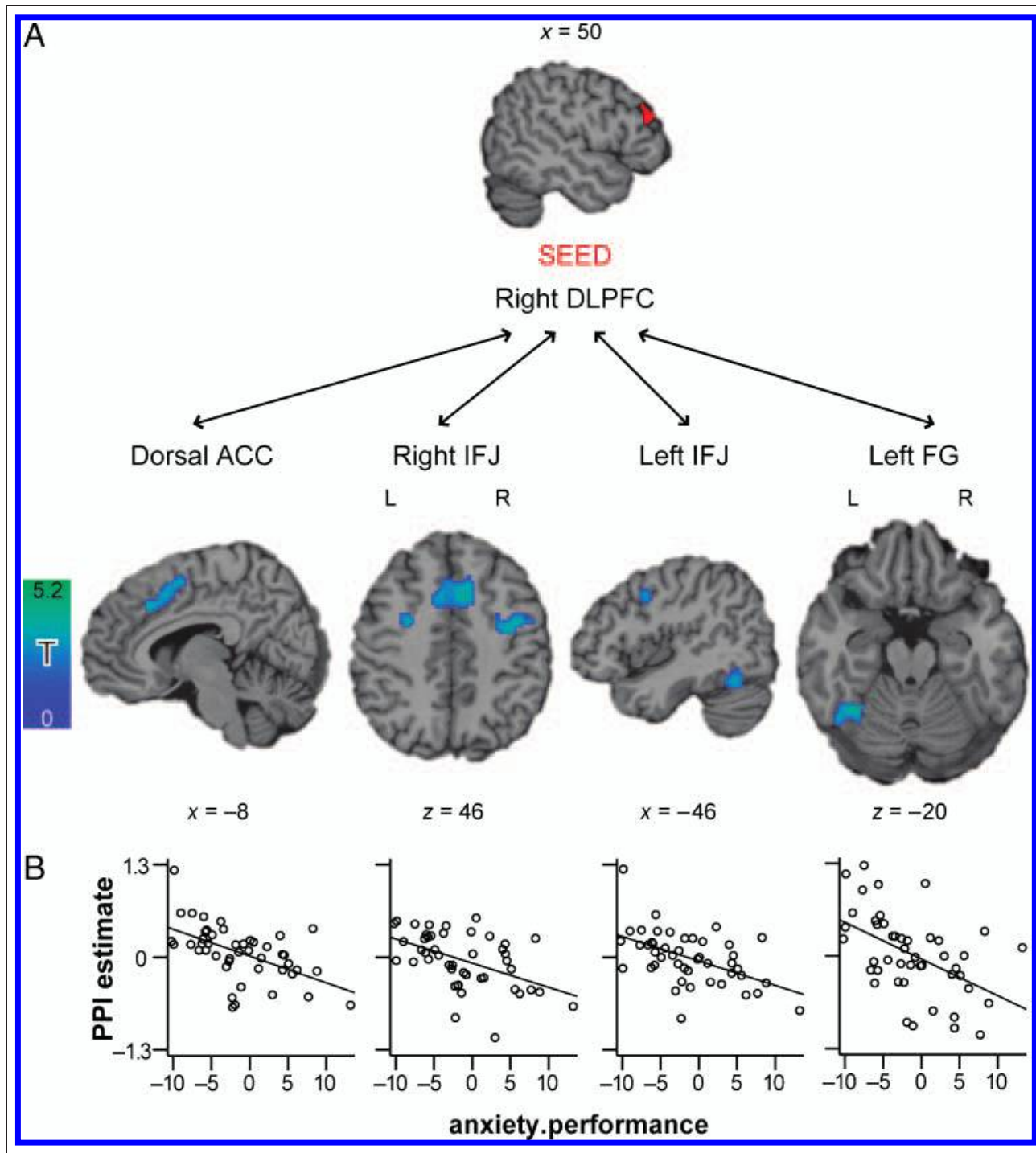

to be attended-word information inherent in the Stroop task stimulus (Polk, Drake, Jonides, Smith, \& Smith, 2008; Harrison et al., 2005). Incongruency-related activation in the BG and cerebellum has been reported less consistently (cf. Polk et al., 2008; Liu, Banich, Jacobson, \& Tanabe, 2006; Van Veen \& Carter, 2005; Pardo et al., 1990; but see Aron, Poldrack, \& Wise, 2009; Aron et al., 2007, for BG role in the inhibition of irrelevant responses).

Table 4. Effects of Trait Anxiety on Functional Coupling in the Stroop Task (Incongruent > Congruent)

\begin{tabular}{|c|c|c|c|c|c|c|c|c|c|}
\hline \multirow[b]{2}{*}{ Brain Region } & \multirow[b]{2}{*}{$B A$} & \multirow[b]{2}{*}{ Hem } & \multicolumn{3}{|c|}{ MNI Coordinates } & \multicolumn{2}{|c|}{ Model $1^{a}$} & \multicolumn{2}{|c|}{ Model $2^{b}$} \\
\hline & & & $x$ & $y$ & $z$ & Voxel $t$ & Cluster Size & Voxel $t$ & Cluster Size \\
\hline dACC & $6 / 8 / 32$ & $\mathrm{~L} / \mathrm{R}$ & 8 & 16 & 50 & 5.20 & 496 & 5.06 & 419 \\
\hline \multirow[t]{2}{*}{ IFJ } & $6 / 8 / 9$ & $\mathrm{~L}$ & -30 & -2 & 42 & 4.72 & 184 & 4.58 & 140 \\
\hline & & $\mathrm{R}$ & 34 & -8 & 46 & 4.04 & 180 & 3.94 & 142 \\
\hline Fusiform gyrus, inferior temporal lobe & 37 & $\mathrm{~L}$ & -36 & -52 & -22 & 4.56 & 143 & 4.45 & 123 \\
\hline
\end{tabular}

$\mathrm{BA}=$ approximate Brodmann's area; Hem = hemisphere; $\mathrm{L}=$ left; $\mathrm{R}=$ right. MNI coordinates refer to the Montreal Neurological Institute template brain included into the SPM5 software package. PPI seed region was in the right DLPFC. All clusters reported show significantly weaker connectivity in higher anxious subjects.

${ }^{a}$ Model 1: Regression of PPI on trait anxiety and behavioral performance.

${ }^{\mathrm{b}}$ Model 2: Regression of PPI on trait anxiety, behavioral performance, and intelligence. 


\section{Impaired Behavioral Performance in Anxious Subjects}

To reiterate, the processing efficiency account distinguishes between performance effectiveness, that is, the quality of performance, and processing efficiency, that is, the amount of resources that have to be invested relative to task performance. Although it is assumed that processing efficiency is reduced in high-anxious persons, the theory does not make a clear prediction as to whether performance effectiveness can be maintained or is impaired as well. Principally, our finding of a stronger performance impairment in the highanxious individuals may be attributable to particularly high levels of anxiety and/or to the high attentional control demands of the task. Anxiety levels may have been amplified by the scanner environment, experienced as threatening by some subjects. Yet, we assume that the effects of anxiety on performance effectiveness are primarily attributable to the specific demands the Stroop task poses on attentional control for the inhibition of irrelevant representations (studies using the Stroop task outside the scanner have found similar effects [e.g., Hopko, Hunt, \& Armento, 2005], whereas studies using different tasks in the scanner have found no effect of anxiety on behavioral performance [e.g., Fales et al., 2008]). Attentional control requirements in our task must have been high, so that anxious subjects could not fully compensate by investing additional resources. However, given the relatively imprecise predictions of the processing efficiency account with respect to performance effectiveness, our primary interest was not in studying overt performance but the efficiency of the underlying neural processing. Thus, we primarily considered the behavioral effects in relation to brain activation strength.

\section{Reduced Neural Efficiency in Anxious Subjects}

The finding of stronger incongruency effects in DLPFC for high-anxious as compared with low-anxious subjects directly supports the predictions of the processing efficiency account. Eysenck et al. (2007) predict that — for a given level of performance effectiveness in a task requiring attentional control for the purpose of inhibition - anxious people should show stronger activation of brain regions implicated in attentional control. The effect was observed in a region of the lateral $\mathrm{pFC}$ that is generally viewed to be crucial for cognitive control, that is, the midportion of the DLPFC (Petrides, 2005; Miller \& Cohen, 2001). We conclude that high-anxious as compared with low-anxious subjects indeed showed an impairment of processing efficiency.

As of now, two previous studies that have used fMRI to investigate the modulation of task-related neural activity by anxiety have led to seemingly contradictory results. One study (Fales et al., 2008) showed stronger task-related activation in a cognitive control network comprising prefrontal and parietal cortical regions for high-anxious individuals during the performance of a demanding working memory task (i.e., a verbal 3-back task), although no performance decrements were observed. The authors interpreted this find- ing as support for the processing efficiency hypothesis. The other study, however, reported weaker prefrontal activation for anxious subjects during the performance of a distracter inhibition task, however, along with a performance deficit (Bishop, 2009). Our results are consistent with those of Fales et al. (2008), in that both studies observe stronger activation of cognitive control regions for anxious subjects in a demanding cognitive task. However, the task employed by Fales et al. (2008) implicates multiple cognitive processes that can potentially be subject to a modulation by anxiety, such as maintenance and updating of working memory processes. By contrast, the comparison of incongruent and congruent Stroop trials used in the current study allows for a more precise definition of the specific cognitive function modulated by anxiety, that is, inhibitory control. Therewith, the results most directly support a specific prediction of attentional control theory (Eysenck et al., 2007). Future studies will have to show whether equivalent effects are found for other domains of executive control functions (cf. Miyake et al., 2000).

The results of the present study, however, seem to be in conflict with the theoretical predictions and empirical data reported by Bishop et al. (2004, 2009). Consistent with attentional control theory (Eysenck et al., 2007), Bishop (2007, 2009) assumes that attentional control is impaired in trait anxious individuals. However, using distracter inhibition paradigms with threat-related (Bishop, Duncan, Brett, et al., 2004) as well as affectively neutral distracters (Bishop, 2009), these authors observed weaker DLPFC activation for anxious subjects in conditions under which, according to the authors, attentional control demands were greatest. For the distracter inhibition task with affectively neutral stimulus material (Bishop, 2009), attentional control demands were expected to be greatest for incongruent as compared with congruent distracter trials under low as compared with high perceptual load. Under these task conditions, Bishop (2009) observed a negative correlation between anxiety and DLPFC activity that seems to be in contradiction to the processing efficiency account as well as to the present results and those of Fales et al. (2008). However, these differences may potentially be reconciled by taking into account the fact that Bishop (2009) varied the attentional control demands of her letter search task not only by introducing conflict resulting from a distracter letter but also by manipulating perceptual demands. On the basis of the assumption that high perceptual load results in only limited processing of distracter stimuli (Lavie, 2005), it was assumed that the higher vulnerability to distracter-related cognitive conflict in anxious individuals manifests itself only under low perceptual load, as only this load condition allows that distracters are processed beyond the perceptual level and, thus, can influence higher-level cognitive processing (cf. Lavie, 2005). Consequently, Bishop (2009) examined the effect of trait anxiety on cognitive conflict (i.e., presence of an incongruent distracter letter) under low (i.e., identifying a target letter among six identical letters) as compared with high perceptual load (i.e., identifying a target letter 
among six different letters) and found a negative effect of anxiety on the interaction of distraction (present $>$ absent) and perceptual load (low $>$ high). If, however, we entertain the alternative interpretation that there is in fact less cognitive conflict in Bishop's (2009) low perceptual load condition (where one distracter letter is opposed to six identical target letters) and that, in the high load condition, processing of the distracter might in fact not be entirely suppressed early in the processing stream but actually induces processing conflict as well, it would be necessary to examine how anxiety modulates the reverse contrast, that is, cognitive conflict under high as compared with low perceptual load. This analysis would result in a positive anxiety correlation, with greater activity in DLPFC for highly anxious persons, and would thus be in line with the empirical data of the present study and that of Fales et al. (2008), as well as with the predictions of the processing efficiency account (Eysenck et al., 2007). Although this alternative interpretation is plausible and would reconcile the seemingly disparate results, it is not fully supported by the behavioral data reported by Bishop (2009). However, the conflict manipulation used by Bishop (2009) was generally weaker than in the present study, as there were no effects of distraction on performance accuracy in that study. Future research will have to explore in more detail the constraints placed on the modulation of prefrontal cognitive processes by anxiety.

The interpretation of the anxiety-related activation differences observed in DLPFC in the current study is complicated by the fact that trait anxiety was significantly correlated with performance accuracy, and the latter was included as a covariate in the regression model. Thus, effects of trait anxiety on brain activation, strictly speaking, reflect an effect of the residual of trait anxiety after variance because of performance differences was partialled out (cf. Miller \& Chapman, 2001). However, the effects of anxiety on DLPFC activation also held when tested in a model including solely trait anxiety as a predictor (MNI peak coordinates: $523626, t(44)=$ $3.59, k=80$ ). We interpret this result of higher activation in the high-anxious subjects in association with worse performance effectiveness as additional support for our conclusions regarding reduced processing efficiency in high-anxious subjects.

Furthermore, it is interesting to note that, in addition to a greater impairment of performance accuracy for incongruent as compared with congruent trials, high-anxious subjects displayed a general trend toward faster responding, possibly reflecting a speed-accuracy trade-off in favor of faster responses at the cost of increased errors (Meyer, Irwin, Osman, \& Kounios, 1988; Wickelgren, 1977). A focus on fast responding in high-anxious subjects might be capable of influencing BOLD signal strength in DLPFC. For example, Van Veen, Krug, and Carter (2008) report that emphasizing speed over accuracy in a Simon interference task (Craft \& Simon, 1970) resulted in greater sustained activation and smaller transient, that is, stimulus-related activation in the DLPFC (and other regions). However, our data show a different pattern of anxiety effects on tran- sient neural responses (i.e., no group difference in congruent trials and an increase of incongruency effects with anxiety), making it unlikely that the anxiety effect on DLPFC activations results directly from a speed-accuracy trade off. Although we cannot investigate in our paradigm the effect of anxiety on sustained baseline activation in DLPFC, it is an interesting open question for future work whether an anxiety-related increase in response speed modulates baseline activation levels.

In summary, our data support the assumption of reduced cognitive processing efficiency in anxious individuals (Eysenck et al., 2007), by demonstrating a reduction in neural efficiency in subjects with greater trait anxiety. Reduced neural efficiency, that is, a compensatory increase in the activation of task-relevant regions, however, is not specific to trait anxiety. Further evidence for compensatory activation strategies in individuals suffering a fundamental detriment in attentional control comes from studies on the neural bases of intelligence and psychopathology. EEG studies on the neural correlates of intelligence found stronger brain activation in less intelligent subjects during a range of challenging cognitive tasks (for a review, see Neubauer \& Fink, 2009a). These findings, too, are interpreted as indicating that less intelligent individuals have to invest more effort to maintain a standard performance level. Imaging studies in psychopathology have as well repeatedly found stronger activation of prefrontal regions in patients (inefficiency in depression: Wagner et al., 2006; Harvey et al., 2005; "hyperfrontality" in schizophrenia: Royer et al., 2009; Schlösser, Koch, et al., 2008; Callicott et al., 2000). Other studies reported "hypofrontality" in psychiatric samples (for reviews, see Ragland, Yoon, Minzenberg, \& Carter, 2007; Manoach, 2003). It remains to be determined under which circumstances cognitive processing is characterized by hyperfrontality versus hypofrontality in these populations. Taken together, the findings from different fields of research on individual differences in cognitive processing (as depending on personality, intelligence, and psychopathology) suggest that the compensatory activation of task-relevant brain regions may be a way to (at least to a certain extent) make up for impairments of cognitive processing and to avoid detriments in overt performance.

\section{Decreased Functional Connectivity Underlying Impaired Neural Efficiency}

In high-anxious individuals, four regions were found to be less strongly coupled with the right DLPFC during incongruent as compared with congruent trials. All four regions, that is, ACC, the left and right IFJ, and the left fusiform gyrus are part of the task-relevant network activated for incongruency in the Stroop task. The finding is consistent with earlier reports showing the importance of DLPFC connectivity for executive control functions in psychiatric samples. Abnormal coupling or "disconnection" (Friston, 1998) has been linked to pathological cognitive processing in disorders such as schizophrenia (Meda et al., 2009; 
Meyer-Lindenberg et al., 2005; Schlösser et al., 2003), depression (Vasic et al., 2009; Schlösser, Wagner, et al., 2008), and anxiety (Etkin et al., 2009; Shaw et al., 2009). In the Stroop task, the functional coupling of DLPFC with the fusiform gyrus during incongruent trials is likely related to the top-down suppression of task-irrelevant stimulus features (i.e., word form or identity), while participants are engaged in color naming (cf. Polk et al., 2008; Harrison et al., 2005). To resolve conflict on incongruent trials and to generally perform well on the Stroop task, there has to be an effective interaction between frontal networks and ventral visual areas-where the frontal brain areas (ACC, DLPFC, and IFJ) detect conflict in processing (ACC) and implement control (DLPFC) over ventral visual areas that process task-irrelevant stimulus features (fusiform gyrus) to update stimulus representations (IFJ). We speculate that the reduced connectivity between the DLPFC and visual areas observed in anxious subjects hinders the inhibition of processing of the not to be attended feature. However, given the correlational nature of the PPI analysis, we cannot test these ideas concerning the direction of causal influences in the network more directly at present. Future research will have to explore the mutual dependencies in more detail.

In anxious subjects, the attenuated functional coupling of the right DLPFC with other task-relevant regions came along with a significantly stronger activation of this region during incongruent trials. We interpret this finding as reflecting a local compensation for deficient connectivity within a distributed task-relevant network. Thus, we propose that the additional effort put into inhibitory control by the anxious subjects (as reflected in increased DLPFC activation) is the consequence of a functional handicap resulting from suboptimal connectivity. In an electrophysiological study on the relationship between neural efficiency and intelligence in healthy adults, Neubauer and Fink (2009b) found a similar pattern. In a figural-spatial task related to fluid intelligence, less intelligent individuals showed stronger relative activation (event-related desynchronization of EEG alpha activity), accompanied by weaker functional connectivity between proximal scalp sites engaged in task performance (event-related EEG phase locking between short-distance frontal recording sites). We propose here that, generally, the impairment of connectivity between task-relevant brain regions is one potential cause of reduced neural processing efficiency. Thus, impairments in processing efficiency (i.e., local increases in brain activation) reflect an attempt to compensate for the less than optimal interaction between distal brain regions that are involved in successful task performance.

\section{A Threat-independent General Impairment of Attentional Control by Trait Anxiety}

Taken together, both our behavioral results and the neural efficiency effects observed in the present study support the hypothesis that anxious subjects indeed suffer from a general impairment of attentional control—demonstrated for the inhibition of prepotent responses to dominant, non-threat-related irrelevant stimulus information in this study. This result is consistent with behavioral findings from other studies (Derryberry \& Reed, 2002; Hopko, Ashcraft, Gute, Ruggiero, \& Lewis, 1998; Fox, 1994) and with the predictions of attentional control theory (Eysenck et al., 2007). Most importantly, we extend the processing efficiency account of cognition and anxiety by demonstrating that the reduced efficiency of regional brain activation is accompanied by impaired functional coupling between the nodes of a task-related cortical system. Thus, processing inefficiency as observed in univariate brain activation patterns likely results from a compensation for suboptimal connectivity within the system.

\section{Acknowledgments}

This work was supported by an Emmy Noether Program grant to C. J. F. (FI 848/3-1) from the German Research Foundation and the German Excellence Initiative.

Reprint requests should be sent to Ulrike Basten, Department of Psychology, Goethe University Frankfurt, Mertonstr. 17, D-60325 Frankfurt, Germany, or via e-mail: basten@psych.uni-frankfurt.de.

\section{REFERENCES}

Aron, A., Poldrack, R. A., \& Wise, S. P. (2009). Cognition: Basal ganglia role. In L. R. Squire (Ed.), Encyclopedia of neuroscience (Vol. 2, pp. 1069-1077). Oxford: Academic Press.

Aron, A. R., Durston, S., Eagle, D. M., Logan, G. D., Stinear, C. M., \& Stuphorn, V. (2007). Converging evidence for a fronto-basal-ganglia network for inhibitory control of action and cognition. Journal of Neuroscience, 27, 11860-11864.

Ashcraft, M. H., \& Kirk, E. P. (2001). The relationships among working memory, math anxiety, and performance. Journal of Experimental Psychology: General, 130, 224-237.

Banich, M. T., Milham, M. P., Atchley, R., Cohen, N. J., Webb, A., Wszalek, T., et al. (2000a). fMRI studies of Stroop tasks reveal unique roles of anterior and posterior brain systems in attentional selection. Journal of Cognitive Neuroscience, 12, 988-1000.

Banich, M. T., Milham, M. P., Atchley, R. A., Cohen, N. J., Webb, A., Wszalek, T., et al. (2000b). Prefrontal regions play a predominant role in imposing an attentional "set": Evidence from fMRI. Brain Research. Cognitive Brain Research, 10, 1-9.

Bar-Haim, Y., Lamy, D., Pergamin, L., Bakermans-Kranenburg, M. J., \& van Ijzendoorn, M. H. (2007). Threat-related attentional bias in anxious and nonanxious individuals: A meta-analytic study. Psvchological Bulletin, 133, 1-24.

Bishop, S. J. (2007). Neurocognitive mechanisms of anxiety: An integrative account. Trends in Cognitive Sciences, 11, 307-316.

Bishop, S. J. (2009). Trait anxiety and impoverished prefrontal control of attention. Nature Neuroscience, 12, 92-98.

Bishop, S. J., Duncan, J., Brett, M., \& Lawrence, A. D. (2004). Prefrontal cortical function and anxiety: Controlling attention to threat-related stimuli. Nature Neuroscience, 7, 184-188.

Bishop, S. J., Duncan, J., \& Lawrence, A. D. (2004). State anxiety modulation of the amygdala response to unattended 
threat-related stimuli. Journal of Neuroscience, 24 , 10364-10368.

Blankstein, K. R., Toner, B. B., \& Flett, G. L. (1989). Test anxiety and the contents of consciousness: Thought-listing and endorsement measures. Journal of Research in Personality, 23, 269-286.

Botvinick, M. M., Cohen, J. D., \& Carter, C. S. (2004). Conflict monitoring and anterior cingulate cortex: An update. Trends in Cognitive Sciences, 8, 539-546.

Callicott, J. H., Bertolino, A., Mattay, V. S., Langheim, F. J., Duyn, J., Coppola, R., et al. (2000). Physiological dysfunction of the dorsolateral prefrontal cortex in schizophrenia revisited. Cerebral Cortex, 10, 1078-1092.

Calvo, M. G. (1985). Effort, aversive representations and performance in test anxiety. Personality and Individual Differences, 6, 563-571.

Calvo, M. G., Ramos, P. M., \& Estevez, A. (1992). Test anxiety and comprehension efficiency: The role of prior knowledge and working memory deficits. Anxiety, Stress \& Coping: An International Journal, 5, 125-138.

Cohen, L., Dehaene, S., Naccache, L., Lehericy, S., DehaeneLambertz, G., Henaff, M., et al. (2000). The visual word form area: Spatial and temporal characterization of an initial stage of reading in normal subjects and posterior split-brain patients. Brain, 123, 291.

Craft, J. L., \& Simon, J. R. (1970). Processing symbolic information from a visual display: Interference from an irrelevant directional cue. Journal of Experimental Psychology, 83, 415-420.

Cremers, H. R., Demenescu, L. R., Aleman, A., Renken, R., van Tol, M. J., van der Wee, N. J., et al. (2010). Neuroticism modulates amygdala-prefrontal connectivity in response to negative emotional facial expressions. Neuroimage, 49, 963-970.

Dale, A. M. (1999). Optimal experimental design for eventrelated fMRI. Human Brain Mapping, 8, 109-114.

De Houwer, J. (2003). On the role of stimulus-response and stimulus-stimulus compatibility in the Stroop effect. Memory \& Cognition, 31, 353-359.

Derrfuss, J. (2005). Functional specialization in the lateral frontal cortex: The role of the inferior frontal junction in cognitive control. Dissertation, Max-Planck-Institut für Kognitions- und Neurowissenschaften, Leipzig.

Derrfuss, J., Brass, M., Neumann, J., \& von Cramon, D. Y. (2005). Involvement of the inferior frontal junction in cognitive control: Meta-analyses of switching and Stroop studies. Human Brain Mapping, 25, 22-34.

Derryberry, D., \& Reed, M. A. (2002). Anxiety-related attentional biases and their regulation by attentional control.

Journal of Abnormal Psychology, 111, 225-236.

Etkin, A., Prater, K. E., Schatzberg, A. F., Menon, V., \& Greicius, M. D. (2009). Disrupted amygdalar subregion functional connectivity and evidence of a compensatory network in generalized anxiety disorder. Archives of General Psvchiatry 66, 1361-1372.

Eysenck, M. W. (1985). Anxiety and cognitive-task performance. Personality and Individual Differences, 6, 579-586.

Eysenck, M. W., \& Calvo, M. G. (1992). Anxiety and performance: The processing efficiency theory. Cognition $\varepsilon$ Emotion, 6, 409-434.

Eysenck, M. W., Derakshan, N., Santos, R., \& Calvo, M. G. (2007). Anxiety and cognitive performance: Attentional control theory. Emotion, 7, 336-353.

Eysenck, M. W., Payne, S., \& Derakshan, N. (2005). Trait anxiety, visuospatial processing, and working memory. Cognition E Emotion, 19, 1214-1228.

Fales, C. L., Barch, D. M., Burgess, G. C., Schaefer, A., Mennin, D. S., Gray, J. R., et al. (2008). Anxiety and cognitive efficiency: Differential modulation of transient and sustained neural activity during a working memory task. Cognitive, Affective \& Behavioral Neuroscience, 8, 239-253.

Fiebach, C. J., Rissman, J., \& D’Esposito, M. (2006). Modulation of inferotemporal cortex activation during verbal working memory maintenance. Neuron, 51, 251-261.

Forman, S. D., Cohen, J. D., Fitzgerald, M., Eddy, W. F., Mintun, M. A., \& Noll, D. C. (1995). Improved assessment of significant activation in functional magnetic resonance imaging (fMRI): Use of a cluster-size threshold. Magnetic Resonance in Medicine, 33, 636-647.

Fox, E. (1993). Attentional bias in anxiety: Selective or not? Behaviour Research and Therapy, 31, 487-493.

Fox, E. (1994). Attentional bias in anxiety: A defective inhibition hypothesis. Cognition E Emotion, 8, 165-195.

Friston, K. J. (1998). The disconnection hypothesis. Schizophrenia Research, 30, 115-125.

Friston, K. J., Buechel, C., Fink, G. R., Morris, J., Rolls, E., \& Dolan, R. J. (1997). Psychophysiological and modulatory interactions in neuroimaging. Neuroimage, 6, 218-229.

Friston, K. J., Fletcher, P., Josephs, O., Holmes, A., Rugg, M. D., \& Turner, R. (1998). Event-related fMRI: Characterizing differential responses. Neuroimage, 7, 30-40.

Harrison, B. J., Shaw, M., Yucel, M., Purcell, R., Brewer, W. J., Strother, S. C., et al. (2005). Functional connectivity during Stroop task performance. Neuroimage, 24 , 181-191.

Harvey, P. O., Fossati, P., Pochon, J. B., Levy, R., Lebastard, G., Lehericy, S., et al. (2005). Cognitive control and brain resources in major depression: An fMRI study using the $n$-back task. Neuroimage, 26, 860-869.

Hopko, D. R., Ashcraft, M. H., Gute, J., Ruggiero, K. J., \& Lewis, C. (1998). Mathematics anxiety and working memory: Support for the existence of a deficient inhibition mechanism. Journal of Anxiety Disorders, 12, 343-355.

Hopko, D. R., Hunt, M. K., \& Armento, M. E. A. (2005). Attentional task aptitude and performance anxiety. International Journal of Stress Management, 12, 389-408.

Kerns, J. G., Cohen, J. D., MacDonald, A. W., III, Cho, R. Y., Stenger, V. A., \& Carter, C. S. (2004). Anterior cingulate conflict monitoring and adjustments in control. Science. 303, 1023-1026.

Kienast, T., Hariri, A. R., Schlagenhauf, F., Wrase, J., Sterzer, P., Buchholz, H. G., et al. (2008). Dopamine in amygdala gates limbic processing of aversive stimuli in humans. Nature Neuroscience, 11, 1381-1382.

Lancaster, J., Summerlin, J., Rainey, L., Freitas, C., \& Fox, P. (1997). The Talairach daemon, a database server for Talairach atlas labels. Neuroimage, 5, S633.

Lancaster, J. L., Woldorff, M. G., Parsons, L. M., Liotti, M., Freitas, C. S., Rainey, L., et al. (2000). Automated Talairach atlas labels for functional brain mapping. Human Brain Mapping, 10, 120-131.

Laux, L., Glanzmann, P., Schaffner, P., \& Spielberger, C. D. (1981). Das State-Trait-Angstinventar, Theoretische Grundlagen und Handanweisung. Weinheim: Beltz Testgesellschaft.

Lavie, N. (2005). Distracted and confused?: Selective attention under load. Trends in Cognitive Sciences, 9, 75-82.

Liu, X., Banich, M. T., Jacobson, B. L., \& Tanabe, J. L. (2006). Functional dissociation of attentional selection within pFC: Response and non-response related aspects of attentional selection as ascertained by fMRI. Cerebral Cortex, 16, 827-834. 
MacDonald, A. W., III, Cohen, J. D., Stenger, V. A., \& Carter, C. S. (2000). Dissociating the role of the dorsolateral prefrontal and anterior cingulate cortex in cognitive control. Science, 288, 1835-1838.

MacLeod, C., \& Donnellan, A. M. (1993). Individual differences in anxiety and the restriction of working memory capacity. Personality and Individual Differences, 15, 163-173.

Maldjian, J. A., Laurienti, P. J., Kraft, R. A., \& Burdette, J. H. (2003). An automated method for neuroanatomic and cytoarchitectonic atlas-based interrogation of fMRI data sets. Neuroimage, 19, 1233-1239.

Manoach, D. S. (2003). Prefrontal cortex dysfunction during working memory performance in schizophrenia: Reconciling discrepant findings. Schizophrenia Research, 60, 285-298.

Mathews, A., \& Mackintosh, B. (1998). A cognitive model of selective processing in anxiety. Cognitive Therapy and Research, 22, 539-560.

McCandliss, B., Cohen, L., \& Dehaene, S. (2003). The visual word form area: Expertise for reading in the fusiform gyrus. Trends in Cognitive Sciences, 7, 293-299.

Meda, S. A., Stevens, M. C., Folley, B. S., Calhoun, V. D., \& Pearlson, G. D. (2009). Evidence for anomalous network connectivity during working memory encoding in schizophrenia: An ICA based analysis. PLoS One, 4, e7911.

Meyer, D. E., Irwin, D. E., Osman, A. M., \& Kounios, J. (1988). The dynamics of cognition and action: Mental processes inferred from speed-accuracy decomposition. Psychological Review, 95, 183-237.

Meyer-Lindenberg, A. S., Olsen, R. K., Kohn, P. D., Brown, T., Egan, M. F., Weinberger, D. R., et al. (2005). Regionally specific disturbance of dorsolateral prefrontal-hippocampal functional connectivity in schizophrenia. Archives of General Psychiatry, 62, 379-386.

Miller, E. K., \& Cohen, J. D. (2001). An integrative theory of prefrontal cortex function. Annual Review of Neuroscience, 24, 167-202.

Miller, G. A., \& Chapman, J. P. (2001). Misunderstanding analysis of covariance. Journal of Abnormal Psychology, 110, 40-48.

Miyake, A., Friedman, N. P., Emerson, M. J., Witzki, A. H., Howerter, A., \& Wager, T. D. (2000). The unity and diversity of executive functions and their contributions to complex "frontal lobe" tasks: A latent variable analysis. Cognitive Psvchology, 41, 49-100.

Nee, D. E., Wager, T. D., \& Jonides, J. (2007). Interference resolution: Insights from a meta-analysis of neuroimaging tasks. Cognitive. Affective \& Behavioral Neuroscience. 7, $1-17$.

Neubauer, A. C., \& Fink, A. (2009a). Intelligence and neural efficiency. Neuroscience and Biobehavioral Reviews 33, 1004-1023.

Neubauer, A. C., \& Fink, A. (2009b). Intelligence and neural efficiency: Measures of brain activation versus measures of functional connectivity in the brain. Intelligence, 37, 223-229.

Öhman, A. (2005). The role of the amygdala in human fear: Automatic detection of threat. Psychoneuroendocrinology, 30, 953-958.

Pardo, J. V., Pardo, P. J., Janer, K. W., \& Raichle, M. E. (1990). The anterior cingulate cortex mediates processing selection in the Stroop attentional conflict paradigm. Proceedings of the National Academv of Sciences. U.S.A., 87, 256-259.

Passamonti, L., Rowe, J. B., Ewbank, M., Hampshire, A., Keane, J., \& Calder, A. J. (2008). Connectivity from the ventral anterior cingulate to the amygdala is modulated by appetitive motivation in response to facial signals of aggression. Neuroimage, 43, 562-570.
Petrides, M. (2005). Lateral prefrontal cortex: Architectonic and functional organization. Philosophical Transactions of the Royal Society of London, Series B, Biological Sciences, 360, 781-795.

Poldrack, R. A., \& Mumford, J. A. (2009). Independence in ROI analysis: Where is the voodoo? Social Cognitive \& Affective Neuroscience, 4, 208-213.

Polk, T. A., Drake, R. M., Jonides, J. J., Smith, M. R., \& Smith, E. E. (2008). Attention enhances the neural processing of relevant features and suppresses the processing of irrelevant features in humans: A functional magnetic resonance imaging study of the Stroop task. Iournal of Neuroscience, 28, 13786-13792.

Ragland, J. D., Yoon, J., Minzenberg, M. J., \& Carter, C. S. (2007). Neuroimaging of cognitive disability in schizophrenia: Search for a pathophysiological mechanism. International Review of Psychiatry, 19, 417-427.

Raven, J., Raven, J. C., \& Court, J. H. (1998). Manual for Raven's progressive matrices and vocabulary scales. Oxford: Oxford Psychologists Press.

Royer, A., Schneider, F. C., Grosselin, A., Pellet, J., Barral, F. G., Laurent, B., et al. (2009). Brain activation during executive processes in schizophrenia. Psychiatrv Research, 173, $170-176$.

Schlösser, R., Gesierich, T., Kaufmann, B., Vucurevic, G., Hunsche, S., Gawehn, J., et al. (2003). Altered effective connectivity during working memory performance in schizophrenia: A study with fMRI and structural equation modeling. Neuroimage, 19, 751-763.

Schlösser, R. G., Koch, K., Wagner, G., Nenadic, I., Roebel, M., Schachtzabel, C., et al. (2008). Inefficient executive cognitive control in schizophrenia is preceded by altered functional activation during information encoding: An fMRI study. Neuropsychologia, 46, 336-347.

Schlösser, R. G., Wagner, G., Koch, K., Dahnke, R., Reichenbach, J. R., \& Sauer, H. (2008). Fronto-cingulate effective connectivity in major depression: A study with fMRI and dynamic causal modeling. Neuroimage, 43, 645-655.

Shaw, M. E., Moores, K. A., Clark, R. C., McFarlane, A. C., Strother, S. C., Bryant, R. A., et al. (2009). Functional connectivity reveals inefficient working memory systems in post-traumatic stress disorder. Psychiatry Research, 172, 235-241.

Spielberger, C. D., Gorsuch, R. L., Lushene, R., Vagg, P. R., \& Jacobs, G. A. (1983). Manual for the State-Trait Anxiety Inventory. Palo Alto, CA: Consulting Psychologists Press.

Spoletini, I., Cherubini, A., Di Paola, M., Banfi, G., Rusch, N., Martinotti, G., et al. (2009). Reduced fronto-temporal connectivity is associated with frontal gray matter density reduction and neuropsychological deficit in schizophrenia. Schizophrenia Research, 108, 57-68.

Stephan, K. E., Baldeweg, T., \& Friston, K. J. (2006). Synaptic plasticity and dysconnection in schizophrenia. Biological Psychiatry, 59, 929-939.

Stroop, J. R. (1935). Studies of interference in serial verbal reactions. Journal of Experimental Psvchologv, 18, 643-662.

Van Veen, V., \& Carter, C. S. (2005). Separating semantic conflict and response conflict in the Stroop task: A functional MRI study. Neuroimage, 27, 497-504.

Van Veen, V., Krug, M. K., \& Carter, C. S. (2008). The neural and computational basis of controlled speed accuracy tradeoff during task performance. Journal of Cognitive Neuroscience, 20, 1952-1965.

Vasic, N., Walter, H., Sambataro, F., \& Wolf, R. C. (2009). Aberrant functional connectivity of dorsolateral prefrontal and cingulate networks in patients with major depression 
during working memory processing. Psvchological Medicine 39, 977-987.

Vul, E., Harris, C., Winkielman, P., \& Pashler, H. (2009). Puzzlingly high correlations in fMRI studies of emotion, personality, and social cognition. Perspectives on Psvchological Science, 4, 274.

Wagner, G., Sinsel, E., Sobanski, T., Kohler, S., Marinou, V., Mentzel, H. J., et al. (2006). Cortical inefficiency in patients with unipolar depression: An event-related fMRI study with the Stroop task. Biological Psychiatry, 59, 958-965.

Ward, B. D. (2000). Simultaneous inference for fMRI data. From afni.nimh.nih.gov/pub/dist/doc/manual/AlphaSim.pdf. Wickelgren, W. (1977). Speed-accuracy tradeoff and information processing dynamics. Acta Psychologica, $41,67-85$.

Williams, J. M., Mathews, A., \& MacLeod, C. (1996). The emotional Stroop task and psychopathology. Psychological Bulletin, 120, 3-24.

Yarkoni, T. (2009). Big correlations in little studies: Inflated fMRI correlations reflect low statistical power-Commentary on Vul et al. (2009). Perspectives on Psychological Science, 4, 294-298.

Yarkoni, T., \& Braver, T. S. (2010). Cognitive neuroscience approaches to individual differences in working memory and executive control: Conceptual and methodological issues. In A. Gruszka, G. Matthews, \& B. Szymura (Eds.), Handbook of individual differences in cognition (pp. 87-108). New York: Springer. 


\section{This article has been cited by:}

1. Kimberly H. Wood. 2015. Neural Substrates Underlying Learning-Related Changes of the Unconditioned Fear Response. The Open Neuroimaging Journal 7, 41-52. [CrossRef]

2. Senqing Qi, Jie Chen, Glenn Hitchman, Qinghong Zeng, Cody Ding, Hong Li, Weiping Hu. 2014. Reduced representations capacity in visual working memory in trait anxiety. Biological Psychology 103, 92-99. [CrossRef]

3. Edna C. Cieslik, Veronika I. Mueller, Claudia Rottschy, Robert Langner, Simon B. Eickhoff. 2014. Three key regions for supervisory attentional control: Evidence from neuroimaging meta-analyses. Neuroscience \& Biobehavioral Reviews . [CrossRef]

4. N. Berggren, N. Derakshan. 2014. Inhibitory deficits in trait anxiety: Increased stimulus-based or response-based interference?. Psychonomic Bulletin \& Review 21, 1339-1345. [CrossRef]

5. Senqing Qi, Cody Ding, Hong Li. 2014. Neural correlates of inefficient filtering of emotionally neutral distractors from working memory in trait anxiety. Cognitive, Affective, \& Bebavioral Neuroscience 14, 253-265. [CrossRef]

6. Margarita Alfimova, Galina Korovaitseva, Tatiana Lezheiko, Vera Golimbet. 2014. Interaction Effects of the COMT and DRD4 Genes with Anxiety-Related Traits on Selective Attention. The Spanish Journal of Psychology 17. . [CrossRef]

7. Kasia Kozlowska, Donna M. Palmer, Kerri J. Brown, Stephen Scher, Catherine Chudleigh, Fiona Davies, Leanne M. Williams. 2014. Conversion disorder in children and adolescents: A disorder of cognitive control. Journal of Neuropsychology n/a-n/a. [CrossRef]

8. R.F. Smallwood, R.M. Hutson, D.A. RobinNeuroimaging Connectivity Analyses and Their Application in Psychiatric Research 2522-2537. [CrossRef]

9. Tom J. Barry, Dirk Hermans, Bert Lenaert, Elise Debeer, James W. Griffith. 2013. The eACS: Attentional control in the presence of emotion. Personality and Individual Differences 55, 777-782. [CrossRef]

10. K. A. Bennion, K. R. Mickley Steinmetz, E. A. Kensinger, J. D. Payne. 2013. Sleep and Cortisol Interact to Support Memory Consolidation. Cerebral Cortex . [CrossRef]

11. Ulrike Basten, Christine Stelzel, Christian J. Fiebach. 2013. Intelligence is differentially related to neural effort in the task-positive and the task-negative brain network. Intelligence 41, 517-528. [CrossRef]

12. S. Markett, B. Weber, G. Voigt, C. Montag, A. Felten, C. Elger, M. Reuter. 2013. Intrinsic connectivity networks and personality: The temperament dimension harm avoidance moderates functional connectivity in the resting brain. Neuroscience 240, 98-105. [CrossRef]

13. Nick Berggren, Nazanin Derakshan. 2013. Attentional control deficits in trait anxiety: Why you see them and why you don't. Biological Psychology 92, 440-446. [CrossRef]

14. C.M. Sylvester, M. Corbetta, M.E. Raichle, T.L. Rodebaugh, B.L. Schlaggar, Y.I. Sheline, C.F. Zorumski, E.J. Lenze. 2012. Functional network dysfunction in anxiety and anxiety disorders. Trends in Neurosciences 35, 527-535. [CrossRef]

15. Ulrike Basten, Christine Stelzel, Christian J. Fiebach. 2012. Trait anxiety and the neural efficiency of manipulation in working memory. Cognitive, Affective, \& Behavioral Neuroscience . [CrossRef]

16. Kimberly H. Wood, Lawrence W. Ver Hoef, David C. Knight. 2012. Neural mechanisms underlying the conditioned diminution of the unconditioned fear response. NeuroImage 60, 787-799. [CrossRef]

17. Roman Osinsky, Helge Gebhardt, Nina Alexander, Jürgen Hennig. 2012. Trait anxiety and the dynamics of attentional control. Biological Psychology 89, 252-259. [CrossRef] 